\title{
New 'Field' of Vocal Music Teaching and Research: Research on the Construction of a Novel Interaction Mode
}

\author{
Donglan $\mathrm{Li}^{1}$ \\ ${ }^{1}$ School of Art, Guangdong University of Foreign Studies, Guangzhou, China \\ Correspondence: Donglan Li, Professor from School of Art, Guangdong University of Foreign Studies, Daxue \\ Cheng Campus, Guangzhou City, 510006, Guangzhou, China. E-mail: dong19621218@126.com
}

Received: September 23, 2015 Accepted: November 10, 2015 Online Published: November 12, 2015

doi:10.5539/elt.v8n12p74 URL: http://dx.doi.org/10.5539/elt.v8n12p74

\begin{abstract}
This paper, as an attempt to find a solution to the problem of 'Identity Crisis' brought about by the traditional spoon-feeding Education Mode, explores to construct a new mode of vocal music teaching characterized by an interaction on an equal and democratic footing between learners and the teacher in light of Habermas' Communicative Action theory. This new mode, taking into consideration students' personalities and characteristics, can help to cultivate their innovative spirit and practical ability, hence enhancing the expressiveness of the teaching content and bettering teaching effect and the quality of vocal music talents.
\end{abstract}

Keywords: Habermas, communicative action theory, vocal music education, creative learning, educational reform

\section{Problem Identified}

There is not much research conducted in the area of the new-type vocal music teaching in the domestic research literature. One strand of such research focuses on a specific area as the research target. An example is the study conducted by Ch. Shi and Sh. Jin, who analyzed the role played by the teacher in vocal music instruction based on a case in the place they live and work in and put forward some representative teaching issues. But due to the restrictive nature of case studies, their study may presumably not be representative or applicable to the teaching practice in other areas. The other strand of research is based on Habermas' Communicative Action theory. A typical example is made by D. Li (2014), who applied the theory into vocal music teaching and constructed a new mode of interaction between students and the teacher as a solution to the identity crisis which had appeared in the field.

The theory of Identity Crisis was proposed by Erik H Erikson, a well-known American psychologist. Identity refers to an adaptive sense of mutual matching and integration between the self-image an individual gains (the psychological self) and the image perceived by others (the reflective self) (Zheng, 2002). According to the theory, when a person's psychological self is inconsistent with the reflective self, he/she will experience mental imbalance, resulting in confusion of self consciousness and inability to clearly understand self positioning and future development and to adapt to the current situation, which is called Identity Crisis. In recent years identity crisis arises in the field of vocal music instruction, manifested by the inconsistence between the theories and techniques imparted and the teaching effect gained. To be more precise, this crisis reflects itself in the following aspects.

Firstly, students' creativity and autonomy are impaired due to the teaching method. In the instruction of vocal music, the teacher tends to overstep the bounds of his/her responsibility and to take care of everything for the students, leading to their lack of creative thinking and independence. The students are constantly required to grasp the knowledge and skills of vocal music imparted, with their own life experience and emotions somewhat neglected. Under the guidance of such a teaching method which emphasizes the mastery of theories and techniques as well as the success in passing examinations, students will show a passive study attitude and take a mechanical learning approach.

Secondly, teaching means is divorced from teaching aims. Vocal music teaching in colleges and universities shows a clear trend of professional educational standardization and being process oriented. Standardized assessment criteria are used to test students' learning, and during the whole teaching process, any individual 
expression is nowhere to be found, in which instruction and conclusion are emphasized, exploration and process are undervalued accordingly. When students' initiative in the efforts to acquire knowledge actively and to learn how to discover, cooperate and be creative is ignored in vocal music teaching, the only thing left will be cramming and standardized examinations.

Thirdly, students are emotionally alienated from their teachers. Due to the enlarged enrolment that began in 1999 at almost all the institutes of higher education in China, students can only get educated in large classes, which is also true of the case with vocal music colleges. This, in a great degree, deviates from the nature of art instruction which requires customized face-to-face interaction since it is a process of art creation and re-creation. This large-class instruction discourages emotional communication between students and the teacher. Worse still, multi campus teaching happens in many universities, in which case students do not have chance to communicate with the teacher out of the classroom, contributing further to their emotional alienation from each other.

Finally, the emphasis is placed on the imparting of professional knowledge and theories are isolated from the living world, which, covering various practical relations between man and the nature, is the environment that people's life depends closely on and the carrier of mutual interaction. As stated above, the teaching practice of vocal music in Chinese tertiary institutions has long been divorced from students' living world, concretely manifested as tedious lecturing of vocal music theories and skills, lacking the spirit of the times, hierarchy and vividness in the content and the method.

\section{Review of Habermas' Theory of Communicative Action}

Identity Crisis in vocal music teaching originates from the adoption of instrumental rational thinking during the teaching process. Instrumental rational thinking treats teaching practice as a tool-making process following a set of technical regulations and rules (Huan, 2002), and in this thinking pattern, students are not respected as the subjects of teaching activities but regarded as tools made by following a certain mechanism for a certain purpose (Han, 2004). When students are perceived as the object to stuff theories and skills in, Identity Crisis occurs. To overcome this crisis, the instrumental rational thinking needs to be cast aside, the relationship between students and the teacher needs to be re-examined and educational regularities need to be abided by as well.

The theory of Communicative Action, proposed by Jürgen Habermas, the most well-known sociologist, philosopher and thinker in contemporary Germany, attaches importance to the equal subject status of the interactive parties, showing full respect to individuals' self consciousness and emotions, realizing the self-perceived value of those involved in the interaction and hence achieving an unity between the psychological self and the reflective self. It provides a good way to overcome the instrumental rational thinking and the Identity Crisis. The application of this theory to vocal music teaching can bring about the following three effects.

Firstly, it makes possible an equal conversational relationship between students and the teacher. The core concept of Habermas' Communicative Action theory is communicative rationality, different from the instrumentally rational thinking pattern in that it regards both parties as an equal conversational participant in the interaction while the latter treats one party as a superior and the other subordinate. In more detail, the conversation between these two equally important participants is free from any compulsion and constraints, and based on the full respect of the self-awareness and emotions of each individual, the two parties can fully communicate and completely understand each other so as to realize their values in social activities and therefore the meaning of life (Yin, 2003).

Secondly, it clarifies the mode of the conversation between students and the teacher, realizing the incorporation of each other's living world. According to the theory, these two equally important participants can have equal and free interaction through honest and sincere dialogues, and after they have understand each other's life experiences and emotions, their living worlds can blend harmoniously.

Thirdly, it contributes to the establishment of a new-fashioned vocal music teaching method through equal dialogues and deepened communication between students and the teacher. The application of this theory can help overcome the Identity Crisis brought about by instrumental rationality and bypass the harms induced by traditional spoon-feeding teaching mode. This new type teaching, students-centered, takes into consideration the expression of students' personalities and respect of their self-images and emotions. It will enable educators to foster students' innovative spirit and practical ability before improving vocal music teaching.

\section{Construction and Discussion of the New Interactive Mode}

Applying Habermas' Communicative Action theory to vocal music teaching is a reform of the traditional teaching mode as it highlights students' status as big players and gives full play to their initiative and creativeness, based on the understanding of students' life experiences and emotions as well as the teaching 
content as the subject around which students and the teacher interact with each other. In this sense, students can experience the essence and value of vocal music teaching content in their own living world and use vocal skills and theoretical knowledge in their own situation so that students' personality development and the progress of vocal music can keep pace with the times in the meanwhile. And the ultimate goal of vocal music teaching will be achieved and a new generation of vocal music talents will be cultivated. The author applies the Communicative Action theory to her own teaching practice trying to provide some ideas on the construction of the new communicative mode of vocal music teaching, which is illustrated as follows.

\subsection{From 'Passive' to 'Active'}

First and the foremost, students' leading role needs to be ensured. In the traditional teaching process, the teacher's spoon-feeding method renders the relationship between students and the teacher one of 'superior' and 'subordinate'. This passive teaching mode wears down students' interest in vocal music learning and imprisons their independent thinking ability. However, the Communicative Action theory emphasizes equal relationship between both sides of the interaction. Teaching itself is an interaction between students and the teacher, with the goal realized through dialogues between both parties. In practical vocal music teaching activities, especially those competitive ones, students' leading role stands out even more, while the teacher, as the organizer and instructor, can create a relaxing and encouraging learning environment based on equal mutual communication to inspire students to experience and feel by themselves.

Second, 'heuristic' teaching and 'creative' learning need to be adopted by which to realize the conversational relationship between students and the teacher. The teacher, by putting Communicative Action theory into practice, can inspire students' thinking and stimulate their curiosity and create an atmosphere in which students will be encouraged to think and to practice creatively. When students' interest in raising questions and seeking answers through exploration and practice is fostered, then a perfect unification of 'heuristic' teaching on the part of the instructor and 'creative' learning on the part of the learner can be achieved. More specifically, the teacher needs to choose interesting topics and to hold discussions to stimulate students' enthusiasm and creativity and to expand their field of vision. He/she also needs to cultivate learners' problem awareness and to integrate vocal music theory teaching with skill training around topics interesting students. What's more, the teacher can encourage students to do research into the subject of interest. Through exploration, they will raise more vocal music topics beyond the scope of the textbook, such as tones, forms, genres, invisible titles, etc.

Third, through close conversations in the instruction for competitions, students will feel emotionally attached to their instructor. The latter generally regards the performance of the former he/she has instructed as the representation of his/her own art practice or even the extension of his/her art life, and so shows special preference to them while the former respects and trusts the latter as an idol and role model. The two will, to some extent, become an inextricable whole with common interests, emotionally linked and growing from love and respect. They share their own experiences and feelings through equal dialogues and barrier-free communication in an atmosphere of mutual respect and love, and they cooperate in the same creative activity of vocal music, resulting in a close combination of teaching process and result and physical and mental development of both the teacher and students, and boosting vocal music instruction to a higher level.

\subsection{Realization of Conversational Relationship}

The Communicative Action theory stresses two-way relationship between two equally important participants instead of unilateral relationship between the superior and the subordinate emphasized in instrumental rational thinking pattern, highlighting mutual interaction, influence and communication (Zeng, 2001). The two-way relationship in vocal music teaching reflects itself on three levels. On the first level, students interact with the teacher via professional language, theoretical knowledge and practice of vocal music. On the second level, the teacher creates an autonomous learning environment in which students' independent awareness will be aroused and creative abilities will be fostered. What the students face is not just an instructor, a piano, a textbook, a video clip and a blackboard. Instead, they stand in an interactive and vivid learning environment with rich information and wide field of vision. They decide on the research topic, make study plan, collect information and do the training all by themselves, and what the teacher needs to do is to provide them with a platform to display their learning results. On the third level, through autonomous research and study, students discover and raise new problems and then work out solutions, whereas the teacher, via generalization and conclusion, accepts those viable ideas and useful suggestions and then employ them in later teaching, achieving the equal interaction between learners and the educator on a higher level.

\subsection{Construction of Students' 'Life World' Field}

According to Habermas, the life world where people live is a continuum of the objective natural world, the social 
world and the subjective emotional world, and all those involved in an interaction can only arrive at mutual understanding in their life world (Habermas, 1994). Learning is not an isolated individual behavior, and the relation between students and the teacher is not a simple teaching-learning one. Only by entering into the life world and integrating into the social and cultural environment can a real interaction be realized between both parties.

Imagination and creativity in vocal music originate from the art's intrinsic innovative nature. Students, in constant pursuit, carefully study basic theories and polish skills, and put what they have learned into practice, making their music activities part of their social life. They then perceive feedback information from society through interactive action, and, based on the information, they adjust and modify their own music activities to realize the sublimation of the art. This is a complete 'emotion-experience-exploration' process. In this process, students integrate the objective natural world, the social world and the subjective emotional world into their living world. Through the adoption of this 'emotion-experience-exploration' teaching mode, the teacher can create a more open, modern and creative context to fully stimulate students' inner learning potential and can offer a more colorful environment to let them, with the wings of imagination, enjoy the experience and appreciate the rich connotation and infinite charm of vocal music.

\subsection{Inspection and Discussion of the Effect}

Habermas believes that learning content is not confined to useful technological knowledge; rather, it contains the practical consciousness which plays a decisive role in the interaction between objects (Habermas, 1994). With their leading role respected, the students' learning initiative needs to be fully mobilized and a practical spirit as well as the capability of designing learning strategies on their own need to be developed. Their experiences in the life world are reflected in the intercourse between the teacher and them, who work together to modify and perfect them till ultimately they achieve the constant development and perfection of vocal music.

\section{Implications}

Vocal music is one of the oldest, the most expressive and appealing art forms. The masterpieces of a country's vocal music all without exception reveal profound cultural, historical and philosophical connotation of this country and show great, unique and endless artistic charm. In vocal music teaching, the teacher should inspire and lead students to design learning subjects according to their own social experiences and based on the grasp of theoretical knowledge and techniques, and then around the subject to think, inquire and explore for the answer. Take 'Orchid Flower', a traditional national vocal music masterpiece in Northern Shaanxi, as an example. It has a beautiful melody and a clear sense of space when it is performed. Students all love it, but they find it difficult to sing it well due to its complexity in skills required to sing it well. When the author, as a college teacher of vocal music, was instructing students, using 'Orchid Flower' as part of the teaching content, instead of emphasizing performance skills, she divided students into several research groups to search historical and cultural information related to this masterpiece, and to design their own research topic around which each member of the group takes a share of the task. After their research, the teacher gave groups individualized guidance, encouraging them to give full play to their artistic imagination and creativity to stage independently dramas, choruses and so forth based on the works. Then she organized a big performance with the whole class in. Such a student-centered teaching mechanism lays stress on students' self awareness and practical learning experience and allows for an honest, sincere and intimate intercourse between learners and the instructor, thus greatly improving the effect of vocal music teaching.

Habermas' Communicative Action theory sheds light on the establishment of a new teaching mode of vocal music, which places great emphasis on students' central role in learning and takes into account their life experiences, creating an open, active, dynamic and two-way teaching environment in which students' artistic quality is enhanced, their inner world is purified, and thus an all-round development is realized alongside the improvement in theoretical knowledge and performance skills. Although the construction of this new teaching mode is still in the preliminary stage, it proves to be a beneficial exploration for the improvement of vocal music teaching effect and the development of talents' quality.

\section{References}

Chunmei, S., \& Shun'ai, J. (2008). Exploration and Construction of New Vocal Music Teaching Mode in Yili Normal University. Journal of Yili Normal University, 4, 12-14.

Donglan, Li. (2014). Construction of a New-type Interaction Mode in Vocal Music Teaching. Journal of Xinghai Conservatory of Music, 2.

Habermas, J. (1994). Communicative Action Theory (1st ed.). (Vol. 1. pp. 144-210). Chongqing: Chongqing 
Press.

Han, X. (2004). A Study on the Relationship between College Students' Self Identity and Mental Health. Populaltion Journal, 1, 34-39.

Huan, P. (2002). Habermas' Communicative Action Theory and Its Significance in China. Gansu Social Sciences, $3,39-42$.

Yin, Z. (2003). The Practical Significance of Habermas' Theory of Communicative Action to the Construction of Moral Education in China. Modern Higher Education, 5, 55-57.

Zeng, X. (2001). Inter-subjectivity in Subjective Education. Journal of Huazhong Normal University, 9, 134-139.

Zheng, F. (2002). Discourse Ethics and School Moral Education. Comparative Education Research, $12,12-17$.

\section{Copyrights}

Copyright for this article is retained by the author(s), with first publication rights granted to the journal.

This is an open-access article distributed under the terms and conditions of the Creative Commons Attribution license (http://creativecommons.org/licenses/by/3.0/). 